Data de recebimento do artigo: 6-12-2017

Data de aceite do artigo: $13-5-2018$

DOI: https://doi.org/10.7769/gesec.v9i2.765

\title{
Competências financeiras: a importância percebida por profissionais de secretariado
}

\author{
Fernando Aguiar Camargo \\ Mestre em Administração de Empresas com Ênfase em Finanças pela Fundação Escola de Comércio \\ Álvares Penteado (Fecap). Professor no Curso de Pós-graduação em Assessoria Executiva da Fecap. \\ E-mail: faguiarcamargo@uol.com.br (Brasil)
}

Edson Ricardo Barbero

Doutor em Administração pela Faculdade de Economia, Administração e Contabilidade da Universidade de São Paulo (USP). Professor do Mestrado Profissional em Administração da Fundação Escola de Comércio Álvares Penteado (Fecap). E-mail: ebarbero@fecap.br (Brasil)

\section{RESUMO}

As mudanças econômicas e políticas afetam a maneira de gerir das empresas e exigem, cada vez mais, profissionais capacitados e que consigam desenvolver competências distintas. O profissional de secretariado caracteriza-se por apresentar conhecimento generalista em diferentes áreas do conhecimento. Porém, não há, na literatura, um trabalho que explore as competências financeiras desse profissional. Nesse contexto, $o$ anseio do presente artigo é contribuir para a percepção da importância das competências financeiras na rotina do profissional de secretariado, por meio de investigação empírica em uma amostra de 272 profissionais. Foram utilizadas, para tal, técnicas de estatística descritiva, análise fatorial exploratória e regressões múltiplas. Como resultado, foram identificadas as oito principais competências financeiras inerentes a esse profissional: $1^{a}$ ) solicitar orçamentos e cotações; $2^{a}$ ) negociar com clientes e/ou fornecedores, considerando a política financeira da organização; $3^{\mathrm{a}}$ ) elaborar relatórios para tomada de decisões com base nos orçamentos e preços; $4^{\mathrm{a}}$ ) elaborar relatórios para reembolso de despesas, considerando a política financeira da organização; $5^{\mathrm{a}}$ ) manusear planilhas eletrônicas (Excel) para cálculos financeiros; $6^{\mathrm{a}}$ ) interpretar informações que contenham juros e/ou acréscimos; $7^{\mathrm{a}}$ ) manusear calculadoras convencionais (operações simples) e $8^{\mathrm{a}}$ ) interpretar informações que contenham descontos. Desenvolveu-se, ainda, uma proposta de Escala de Competências Financeiras para Profissionais de Secretariado. Por fim, as contribuições são: facilitar a identificação das principais competências financeiras, inclusive para a área de recursos humanos, identificando assim profissionais mais preparados e guiar as instituições de ensino que oferecem os cursos de secretariado para identificar se as competências financeiras aqui apontadas são trabalhadas nos cursos.

Palavras-chave: Profissional de secretariado. Finanças. Competências financeiras. Análise fatorial exploratória. Escala de competências financeiras. 


\title{
Financial skills: the importance to the secretarial professionals
}

\begin{abstract}
Economic and political changes affect the way that business are managed and require better qualified professionals who have the ability to develop different skill sets. The secretarial professional has the characteristic of possessing general knowledge in different areas. However, we do not find any literature about financial skills required for the profession. Based on this context, the goal on this paper is to contribute to understanding the importance that financial skills play in the routine of the secretarial professional. The application of descriptive statistical technics, exploratory factorial and multiple regression analysis to empirical data gathered from a sampling of 274 professionals, resulted in the identification of eight main elementary financial skills for this profession: 1) request quotes and estimates; 2) negotiate with customers and/or providers, as per the organization financial policies; 3) create reports regarding quotes and prices to assist in decision making 4) create reimbursements reports following the organization financial policy; 5) use of electronic spreadsheets (Excel) for financial calculations; 6) interpret information regarding interest rates and/or price adjustments; 7) use of common calculator (simple operations) and 8) interpret information with discounts. A Financial Skills Scale for Secretarial Professionals was also developed. The contributions are: to facilitate the identification of the main financial skills, helping human resources professionals to identify the best professionals and to guide the universities that offer the secretarial courses to identify if the financial skills mentioned are taught in the courses they provide.
\end{abstract}

Keywords: Secretarial professional. Finances. Financial skills. Exploratory factorial analysis. Financial skills scale for secretarial professionals.

\section{Como referenciar em APA:}

Camargo, F. A. \& Barbero, E. R. (2018). Competências financeiras: a importância percebida por profissionais de secretariado. R.G.Secr.,GESEC, 9(2). DOI:

\section{Como referenciar em ABNT:}

CAMARGO, F. A.; BARBERO, E. R. Competências financeiras: a importância percebida por profissionais de secretariado. R.G.Secr.,GESEC, v. 9, n. 2, 2018. DOI:
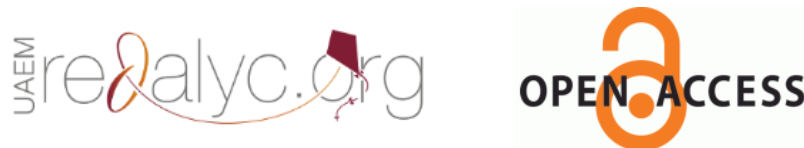


\section{Introdução}

Com o avanço tecnológico - internet e conectividade - e consequentemente maior automação dos processos nas empresas, aumentou a discussão sobre quais competências este profissional detém e como pode cooperar com as empresas. Dessa forma, uma definição generalizada de quem são os profissionais de secretariado e quais suas principais competências pode ser encontrada na Classificação Brasileira de Ocupações (CBO), como se segue:

Assessoram os executivos no desempenho de suas funções, atendendo pessoas (cliente externo e interno), gerenciando informações, elaboram documentos, controlam correspondência física e eletrônica, prestam serviços em idioma estrangeiro, organizam eventos e viagens, supervisionam equipes de trabalho, gerem suprimentos, arquivam documentos físicos e eletrônicos, auxiliando na execução de suas tarefas administrativas e em reuniões (CBO, 2002).

Ainda no contexto secretarial, existem algumas discussões acerca das competências do profissional: dentro de projetos sustentáveis (Todorov, Kniess, \& Chaves, 2013), sobre as competências gerenciais desenvolvidas pelo profissional (Barros, Silva, Lima, \& Brito, 2013), a partir da perspectiva dos gestores dentro de instituições federais de ensino superior (Leal \& Fiates, 2013), no âmbito das universidades, debatendo competências exigidas e perfil (Leal \& Dalmau, 2014) e, por fim, na gestão por competência em empresas de prestação de serviços (Moura \& Sobral, 2014). Porém, nenhum dos trabalhos discutiu a possibilidade de explorar a percepção de importância das competências financeiras dentro da rotina secretarial.

Livros e trabalhos acadêmicos citam diferentes competências desse profissional, mas, em resumo, as competências e habilidades desenvolvidas em um estudante, posteriormente profissional de secretariado, segundo a Resolução no 3, de 23 de junho de 2005, do Ministério da Educação (MEC), são: “capacidade de articulação, visão generalista, funções gerenciais, raciocínio lógico, crítico e analítico, liderança, gerenciamento de informações, gestão e assessoria administrativa, capacidade de maximização e otimização, iniciativa, criatividade, determinação e vontade de aprender" (Resolução n 3, 2005). Contudo, não é citada nenhuma competência ligada especificamente às rotinas financeiras.

Considerando a lacuna apresentada, o trabalho tem como objetivo investigar a importância das competências financeiras pertencentes às rotinas do profissional de secretariado. $\mathrm{O}$ artigo busca, também, em seus objetivos específicos, propor uma escala de competências financeiras, além de testar se fatores como idade, escolaridade, ocupação, renda 
e ramo de atuação da empresa influenciam as respostas e apresentam alguma relação estatística com os fatores da escala.

Em complemento, o único trabalho na área secretarial que tem como cerne a importância do estudo das competências financeiras é o de Cielo e Cielo (2007), que aborda essa lacuna de maneira preliminar, limitando-se a uma pesquisa bibliográfica em trabalhos que não são da área secretarial. Logo, apenas demonstram a importância do conhecimento em finanças para os profissionais que ocupam posições estratégicas nas empresas, sem ter como foco específico o secretariado.

Assim, as perguntas que norteiam o presente artigo são: a) Qual a importância percebida das competências financeiras para profissionais de secretariado? b) Existe alguma competência percebida mais ou menos importante a esse profissional? Para responder a tais questões, foi elaborado um questionário estruturado, aplicado a estudantes e profissionais de secretariado atuantes no Brasil.

Como contribuição teórica, este trabalho busca mapear quais são as competências financeiras mais importantes, na visão dos profissionais de secretariado. Já a contribuição prática busca: a) facilitar a identificação das principais competências financeiras dos profissionais de secretariado, bem como os profissionais mais preparados para o mercado de trabalho; b) facilitação para a área de recursos humanos na identificação das principais competências financeiras desses profissionais; e, por fim, c) guiar as instituições de ensino que oferecem os cursos de secretariado para identificar se as competências financeiras aqui apontadas são trabalhadas nos cursos.

Dessa forma, este estudo apresenta, em sua fundamentação teórica, o conceito de competência, o histórico e a evolução do secretariado, além de considerações sobre as competências financeiras. $\mathrm{Na}$ seção seguinte, serão explorados os procedimentos metodológicos para criação do instrumento e validação de seu conteúdo. Logo após, serão discutidos os resultados da aplicação do instrumento, além da análise estatística, análise fatorial exploratória e suas regressões múltiplas. Finalizando, serão pontuadas as principais considerações, bem como sugestões para pesquisas futuras.

\section{Conceito de competência e suas escolas teóricas}

A discussão acerca de competências não é recente, segundo Morais, Melo e Bianco (2015), uma vez que, na abordagem taylorista, já havia de alguma forma a escolha do melhor 
trabalhador para determinada função - que exigia certa qualificação - ou seja, mesmo de forma implícita os patrões já selecionavam os colaboradores visualizando sua aptidão e/ou capacidade.

Nesse contexto, o debate sobre competências começa com McClelland (1973), evolui com Spencer e Spencer (1993), abordando competência no trabalho e, mais tarde, com Boyatzis (2008), discutindo sobre as competências do século XXI. Apesar do tema ser relatado no ambiente corporativo, existem poucos estudos acadêmicos com a intenção de validar competências, visto que consultores de Recursos Humanos, principais interessados no assunto, têm pouca paciência para o processo de documentação científica (Boyatzis, 2008).

Assim, o conceito de competência pode ser pensado como um conjunto de Conhecimentos, Habilidades e Atitudes (CHA), que justificariam bom desempenho, na medida em que as pessoas com maior destaque seriam explicadas com base na inteligência e na personalidade. Assim, diante do levantamento desses fatos, pode-se considerar a competência como algo individual, já que é um estoque de recursos adquirido pelo indivíduo. Porém, esse contexto não é suficiente para atender à demanda por inovação e também por flexibilidade, características presentes nas empresas globalizadas (Boyatzis, 2008).

Ainda nessa abordagem, é importante ressaltar que, nos anos de 1990, a literatura europeia focou em três pontos de mudança na forma de trabalho de maneira geral, que contribuem para o surgimento das competências para gestão das organizações, a saber: evento, como aquilo que ocorre de maneira não programada; comunicação, como compartilhamento de objetivos organizacionais; e serviço, para atender a clientes externos e internos participando em todas as atividades (Fleury \& Fleury, 2004). Essa contribuição da literatura francesa vem ao encontro de características esperadas nos profissionais de Secretariado Executivo e também refletem competências adquiridas ou otimizadas, seja pela sua formação ou por sua capacidade de aprendizagem.

\section{Competências individuais}

É importante entender a relação entre competência e estratégia, para que seja possível compreender como esse dueto interage com a competitividade de uma organização, que pode ser formada pelo conjunto de competências e estratégias que se retroalimentam ao longo de um processo. Assim, diferentes estratégias geram a necessidade de novas competências e essas interagem com a estratégia, fazendo com que aconteça uma avaliação e readequação constante. (Fleury \& Fleury, 2004). Desse modo, os profissionais têm necessidade de desenvolver novas 
competências para se adaptar às constantes mudanças no ambiente corporativo. Empresas criam novas estratégias para se destacar frente à concorrência e precisam de colaboradores preparados para acompanhar tais mudanças e desenvolvimento.

Nesse contexto, segundo Dutra, Hipólito e Silva (2000), a competência está relacionada à atuação profissional das pessoas, que usam seus pontos fortes não apenas para se enquadrar às estratégias da empresa, mas também para possibilitar realização e felicidade pessoal. Portanto, pode-se relacionar a ascensão profissional a uma maior capacidade mental e, com isso, a possibilidade de ser cada vez mais um profissional estrategista, usufruindo da experiência, conhecimento e competências adquiridas.

Assim, de acordo com Fleury e Fleury (2004), as competências organizacionais estão relacionadas ao desenvolvimento das competências individuais e da realidade vivida pelos profissionais. Esse pensamento vai ao encontro do momento atual (2017), em que o Brasil passa por uma instabilidade econômica e financeira e as competências profissionais são cada vez mais exigidas.

Por fim, vale ressaltar que Fernandes, Fleury e Mills (2006) demostram que o conceito de competência leva ao de desempenho, que está estritamente ligado aos resultados atingidos por uma organização em determinado período. Esta temática é corroborada por Bilert e Biscoli (2012), Leal e Dalmau (2014), Pereira e Silva (2014) e Moreira, Santos e Moretto Neto (2015), cujos estudos abordam o perfil e atuação dos profissionais de secretariado em áreas administrativas e financeiras e reafirmam a participação desses profissionais na entrega e nos resultados das empresas.

\section{Profissional de secretariado}

A palavra secretário tem origem no latim - Secretarium e Secretum - significando, respectivamente, lugar retirado, conselho privado e segredo, o que vem ao encontro da origem da profissão que se deu com os escribas - considerados os precursores do profissional de Secretariado Executivo - no antigo Egito. Naquela época, para se ocupar o cargo de escriba, fazia-se necessário estudar filosofia, história, aritmética, línguas e processos dos templos e governo, características essas de um profissional multifacetado e com competências distintas, que se aproximam dos profissionais atuantes na área de secretariado no século XXI (Bilert \& Biscoli, 2012; Bonzanini, 2011; Cielo, Schmidt, \& Wenningkamp, 2014; Fontanella, 2012; Mascarenhas, Sepulveda, \& D’Assumpção, 2011; Sabino \& Andrade, 2011). 
Ainda nesse contexto, somente após as duas grandes guerras mundiais, a profissão de secretário passou a se destacar. Com a falta de mão de obra masculina, as mulheres começaram a integrar, cada vez mais, o mercado de trabalho e a assumir as mais diversas funções, inclusive a de secretária, antes exercida por homens (escribas). No Brasil, o secretariado teve suas primeiras aparições em 1950, com as mulheres trabalhando essencialmente em empresas familiares. Só em 1970, após a criação da Associação das Secretárias do Rio de Janeiro, a profissão começa a ser percebida nacionalmente XXI (Bilert \& Biscoli, 2012; Bonzanini, 2011; Cielo, Schmidt, \& Wenningkamp, 2014; Fontanella, 2012; Mascarenhas, Sepulveda, \& D’Assumpção, 2011; Sabino \& Andrade, 2011). Também nessa década o profissional passa a ter atuação mais dinâmica e menos operacional.

Contudo, segundo Bilert e Biscoli (2012), Cielo, Schmidt e Wenningkamp (2014) e Sabino e Andrade (2011), a consolidação da profissão de Secretariado Executivo se deu em 30 de setembro de 1985, por meio da Lei $n^{\circ} 7.377$ - posteriormente complementada pela Lei $n^{\circ}$ 9.261, de 10 de janeiro de 1996, pela qual o secretariado deixa de ser função e passa a ser profissão devidamente regulamentada. Outro marco foi a publicação do Código de Ética Profissional, no Diário Oficial da União, de 7 de junho de 1989, regulando a moral e a conduta desses profissionais, o que reforça a importância da profissão.

Nesse sentido, antes de focar nas competências do profissional de secretariado, vale ressaltar que, de acordo com Gretha-Taylor (2008), competência não é só conhecimento, habilidade e atitude, mas remete também ao desempenho e está sempre visando o futuro, ideia corroborada por Santos (2014), que completa tal pensamento relacionando competências com eficácia no trabalho. Tal reflexão é importante, visto que as competências financeiras são cada vez mais exigidas em um universo onde as empresas buscam profissionais que possam alcançar bom desempenho, mesmo em situações adversas.

Fato interessante dentro da carreira do profissional de secretariado, que tem formação generalista e pode atuar em diferentes atividades, é que esse profissional acaba se moldando e adquirindo algumas competências do setor em que trabalha ou mesmo do nível hierárquico onde está inserido. Segundo Moreira, Rodrigues, Vale e Rosa (2016), pode-se observar correlação entre as competências do secretário executivo e as do middle manager, ou seja, podem-se identificar competências gerenciais e também uma vertente financeira, quando abordado o tema competências estratégicas, por exemplo.

Assim, focando nas competências do secretário executivo, é possível listar conhecimentos, habilidades e atitudes em diferentes áreas do conhecimento, tais como: 
a) capacidade de adaptação cultural; b) gestão de políticas e de planejamentos estratégicos; c) gestão de pessoas; d) articulação e negociação com atores importantes e estabelecimento de parcerias sustentáveis; e) ética e responsabilidade social; f) administração dos recursos; g) condições de lidar com tecnologias; h) conhecimento do campo de atuação; i) coordenação de projetos; j) atendimento especializado; k) capacidade de prestação de serviços em idiomas estrangeiros; 1) coordenação de eventos, visitas e viagens; m) capacidade de lidar com mudanças e lidar com imprevistos e n) conhecimento da estrutura e dos processos organizacionais (Leal \& Moraes, 2017 p. 156-157).

Porém, o presente trabalho se propõe a mensurar competências financeiras, logo, essa será sua limitação. O tema é relevante, pois, segundo Moreira et al. (2016), destaca-se o profissional que consegue desenvolver, entre outras competências, raciocínio lógico e habilidade em: administração, economia, contabilidade, finanças e matemática financeira. As autoras ainda destacam a importância de se conhecer a empresa e ter uma visão da totalidade do negócio.

Complementando, Rodrigues, Rosa, Ferko e Melo (2017) constataram que habilidade com finanças e cálculos são competências presentes e requeridas em profissionais atuantes no mercado secretarial, assim como Schmitz, Battisti e Santos (2015) já haviam identificado que tal profissional pode atuar como consultor e precisa de conhecimento em gestão, com foco econômico, contábil e administrativo.

\section{Competências financeiras}

O tema competências financeiras se confunde, em alguns casos, com educação financeira, que versa, entre outros tópicos, sobre como as pessoas utilizam seu dinheiro ou, ainda, em que fatores são baseadas as suas decisões. Neste estudo, será abordado o conceito de competência financeira como as habilidades, conhecimentos e atitudes que o profissional de secretariado desenvolve em sua formação e que, posteriormente, podem ser exigidas e complementadas em sua atuação profissional, relacionadas às rotinas financeiras das empresas.

Ainda na revisão da literatura, não foi encontrada uma definição clássica e sustentada por teoria para o termo "competência financeira". A teoria mais relacionada versa sobre as competências do contador, demonstrando, curiosamente, que há carência de estudos sobre o tema e que a maioria deles tratam da função do profissional e não do fator competência, além de afirmar que faltam estudos empíricos com esse objetivo (Cardoso, Riccio, \& Albuquerque, 2009). Mesmo estudos mais recentes (Laffin, 2015) preconizam que o debate sobre competências do contador precisa ser melhorado. 
Complementando, foram encontrados alguns trabalhos que versam sobre o tema: Almeida (2010) cita finanças relacionando a atuação do profissional em um mundo globalizado; Santos (2011) aborda a importância de contabilidade e finanças fazerem parte da formação; Faria, Baêta e Faria (2015) destacam a necessidade de se conhecer sobre economia, contabilidade e finanças para se encaixar aos perfis das organizações; Euflausino e Silva (2015), analisando anúncios de vagas, citam que esse profissional deve conhecer sobre finanças; e, por fim, Silva, Barros e Nascimento (2016), em seu estudo bibliográfico, encontram apenas uma publicação (livro) voltada especificamente para finanças com foco em secretariado, datada de 2009.

Nesse contexto, Todorov, Martins, Genghini, Martins e Kniess (2016) reafirmam a necessidade de o profissional de secretariado conhecer sobre finanças, tanto quanto Rodrigues e Lavarda (2016), que citam a importância em lidar com a gestão financeira. Assim, é possível notar o quanto as competências financeiras são importantes e pouco exploradas, em se tratando de secretariado executivo. Por essa razão, este trabalho propõe uma maior discussão acerca de finanças e secretariado, focando na importância da relação existente entre as duas áreas e em quais competências são requeridas e exploradas no desempenho da função.

Cabe ressaltar que, mesmo não encontrando trabalhos relacionando secretariado e finanças de maneira direta, segundo Dodman (2016), competência é a junção de conhecimentos, habilidades e atitudes que podem ser aprendidos por meio de práticas e fatos relacionados ao trabalho e/ou estudo. Isso permite inferir que esse profissional vem desenvolvendo suas capacidades financeiras, diante das constantes mudanças econômicas vividas no Brasil desde 2008 e da necessidade de adaptabilidade a novos cenários, que exigem colaboradores cada vez mais multifuncionais, com conhecimento generalizado em diferentes áreas do conhecimento.

\section{Procedimentos Metodológicos}

A pesquisa, no presente estudo, caracteriza-se por seu método descritivo, sua abordagem exploratória e seu procedimento quantitativo, visto que tenta mensurar um comportamento e um conhecimento relacionados às rotinas de trabalho do profissional de secretariado. Essa natureza de pesquisa faz um levantamento de questões relacionadas a quanto ou com que frequência o tema pesquisado aparece no instrumento escolhido (Cooper \& Schindler, 2016). 


\section{Criação do instrumento}

O instrumento de coleta utilizado foi um questionário estruturado do tipo survey. A escolha dessa ferramenta se deu pela facilidade em atingir um número maior de pessoas, simultaneamente, obtenção de respostas mais rápidas e tentativa de facilitar ao máximo o acesso aos respondentes. O questionário foi elaborado com questões fechadas, ou seja, com opções de resposta, utilizando-se a graduação baseada na Escala de Valores relativos ao Trabalho (EVT), que visa compreender o que é importante para as pessoas no ambiente de trabalho (Cooper \& Schindler, 2016; Siqueira, 2009).

Para formulação das afirmações - itens - que fazem parte deste instrumento, o documento base utilizado foi o Plano de Curso para a Habilitação Profissional de Técnico em Secretariado, elaborado pelo Centro Estadual de Educação Tecnológica Paula Souza (CEETPS) (2011). Nesse plano são relacionadas algumas competências e habilidades (e também bases tecnológicas) a serem desenvolvidas pelos alunos que ingressam no curso técnico em secretariado.

Entre as justificativas para o uso do plano de curso (CEETPS, 2011), estão: a) o plano é elaborado buscando mapear a evolução do profissional e também o mercado de atuação; b) fazem parte da elaboração profissionais de secretariado com formação e experiência na área; c) o CEETPS usa o plano como base para todos os cursos técnicos em secretariado a nível estadual (São Paulo); e d) por ser um estudo inicial na temática de finanças, optou-se por buscar competências menos complexas.

O uso de um documento que tem como base o ensino técnico é justificado também com apoio na Lei de Regulamentação da Profissão (Lei n ${ }^{\circ}$ 7.377, de 1985 e Lei nº 9.261, de 1996), que dispõe sobre o exercício da profissão de secretariado, relacionando as atividades pertinentes ao Secretário Executivo e ao Técnico em Secretariado. Nota-se, pela redação, que as funções do técnico em secretariado são também exercidas pelo secretário executivo, porém com um nível maior de especialização. Assim, optou-se pelo uso de atividades técnicas no instrumento para ter maior aderência à amostra utilizada (diferentes níveis profissionais), facilitando o entendimento dos respondentes e explorando o uso de competências mais generalizadas e abrangentes.

Esse instrumento também usa como base a Taxonomia de Bloom, que define conhecimento em dois tipos: a) como processo e b) como conteúdo assimilado. Desse modo, o questionário visa não só investigar o conhecimento e as habilidades aprendidas na formação 
(processo), mas também aquelas habilidades adquiridas com a experiência profissional (conteúdo assimilado) (Ferraz \& Belhot, 2010).

\section{Validação de conteúdo}

Após a construção do questionário, este foi enviado a especialistas - que atuam corporativamente e/ou academicamente na área de secretariado - para que fosse avaliado. Nesta etapa, espera-se que os especialistas contribuam sugerindo mudanças ou adaptações buscando a mensuração do objeto de estudo (Campos, Barbero, \& Lourenço, 2015; Costa, 2013).

Importante ressaltar que o questionário foi avaliado por oito especialistas. Todos eles são docentes do curso de secretariado, sendo três deles também coordenadores dos cursos. Uma outra característica em comum entre os especialistas é que todos têm algum vínculo ou relacionamento com a Associação Brasileira de Pesquisa em Secretariado (ABPSEC).

Sequencialmente, foi solicitado aos especialistas que julgassem alguns critérios levados em consideração na construção do instrumento, tais como: 1) linguagem simples e objetiva; 2) perguntas e ou afirmações, curtas e diretas; 3) possível ambiguidade entre itens (Campos et al., 2015); 4) adequação ao público-alvo: profissionais de secretariado; e 5) documento-base utilizado. Foi ressaltada, também, a importância de acrescentar ou subtrair qualquer item (afirmação) que fosse julgado como pertinente ou impróprio.

Após análise dos especialistas, as principais contribuições foram: acrescentar objetivo da pesquisa, escopo, temas abordados, público-alvo, tempo médio de resposta e dados para contato do pesquisador no cabeçalho. Já nas questões (afirmações) foram sugeridos: colocar legenda para siglas financeiras, como o IPCA (Índice de Preços ao Consumidor Amplo), alterar a sequência de algumas afirmativas para não confundir o entendimento do respondente, unificar algumas afirmações com significados próximos, excluir afirmações muito específicas e, por fim, acrescentar uma resposta aberta (outros) nos dados demográficos.

\section{Pré-teste}

O instrumento criado foi aplicado a profissionais com perfil similar àqueles pertencentes à amostra, com a intenção de avaliar o tempo gasto para resposta do questionário, assim como eventuais dificuldades na compreensão de algum item. Assim, seria possível ajustar melhorando a aderência à amostra, e facilitando a compreensão dos respondentes (Costa, 2013). 
Essa fase foi realizada com 1,3\% da amostra total, conforme Cooper e Schindler (2016). O perfil dos respondentes, resumidamente, é: formação distinta, ou seja, sem formação específica, com formação técnica e com graduação em Secretariado Executivo e graduação em Administração. Outra característica importante é que os respondentes estão cursando pósgraduação na área de secretariado/assessoria executiva.

O tempo médio de resposta foi de oito minutos e quarenta e seis segundos e nenhum dos respondentes apresentou dúvidas quanto à redação e/ou conceitos abordados no questionário. Importante ressaltar que um dos respondentes está em sua primeira experiência profissional na área secretarial, o que possibilitou também que o questionário fosse avaliado por pessoas com experiências profissionais distintas, ou seja, desde pessoas com pouca experiência até pessoas com mais de 10 anos de atuação.

\section{Técnicas estatísticas}

Após devidamente coletados, seguindo os estudos de Campos et al. (2015) e Costa (2013), os dados receberam tratamento estatístico no software SPSS - Statistical Package for the Social Sciences, iniciando-se pelas estatísticas descritivas e também análise das variáveis, na tentativa de identificar possíveis valores ausentes e também outliers.

$\mathrm{Na}$ sequência, os dados foram submetidos à análise fatorial exploratória, método estatístico multivariado, que define fatores comuns entre os dados, utilizado para melhorar a análise de um grande número de variáveis. Com essa análise é possível identificar dimensões e através delas conhecer o grau em que cada variável é explicada por cada dimensão identificada. Além disso, o método ajuda na redução dos dados e na interpretação das relações existentes entre as variáveis (Hair, Anderson, Tatham, \& Black, 2005).

Foi aplicado, ainda, o método de regressões lineares múltiplas, usado para estudar a relação entre variáveis (Wooldridge, 2014), em que se buscou entender a relação entre as respostas coletadas e os dados dos respondentes. Investigou-se também a relação entre os fatores identificados na análise fatorial e as características dos respondentes, a fim de encontrar características similares entre a amostra.

\section{Resultados e Discussão}

Para apresentação dos resultados, primeiro serão expostos os dados demográficos dos respondentes e suas principais características. O questionário recebeu um total de 304 respostas, 
das quais 272 foram consideradas válidas e, assim, usadas em todas as análises que serão demonstradas nesta seção.

Participaram da pesquisa 253 mulheres (93\%) e 19 homens (7\%). Desse total, 39\% têm idade entre 31 e 40 anos. Quanto à escolaridade, $40 \%$ possuem graduação completa, sendo que bacharelado em secretariado foi apontado por $61 \%$ como formação ou curso em andamento, atualmente. Com relação à ocupação atual, $65 \%$ da amostra estão empregados com carteira assinada e $40 \%$ têm renda bruta mensal entre dois e cinco salários mínimos.

Investigando sobre as empresas dos entrevistados, verificou-se que $45 \%$ da amostra trabalham em empresas prestadoras de serviço e $43 \%$ trabalham em empresas de grande porte, com mais de 500 funcionários. Quando perguntados sobre o cargo exercido, $51 \%$ responderam que exercem o cargo de Secretário(a) e 76\% dos entrevistados que atuam ou atuaram em sua última experiência no estado São Paulo.

\section{Análise de estatísticas descritivas}

Na Tabela 1 são apresentadas as estatísticas descritivas sobre as questões que investigavam a percepção da importância das competências financeiras para profissionais de secretariado.

Tabela 1 - Análise estatística das respostas do survey.

\begin{tabular}{|l|l|c|c|c|}
\hline Item & \multicolumn{1}{|c|}{ Affirmação } & Média & $\begin{array}{c}\text { Desvio } \\
\text { Padrão }\end{array}$ & $\begin{array}{c}\text { Coeficiente } \\
\text { Variância }\end{array}$ \\
\hline C01 & Interpretar indicadores financeiros, tais como: CDI, SELIC e IPCA. & 3,17 & 1,01 & 0,32 \\
\hline C02 & Interpretar taxas, tais como: juros ou câmbio. & 3,76 & 0,91 & 0,24 \\
\hline C03 & Interpretar informações que contenham porcentagens. & 3,94 & 0,87 & 0,22 \\
\hline C04 & Interpretar informações que contenham descontos. & 4,00 & 0,85 & 0,21 \\
\hline C05 & Interpretar informações que contenham juros e/ou acréscimos. & 4,04 & 0,86 & 0,21 \\
\hline C06 & $\begin{array}{l}\text { Elaborar cálculos de operações financeiras (por exemplo: } \\
\text { financiamento). }\end{array}$ & 3,40 & 1,09 & 0,32 \\
\hline C07 & $\begin{array}{l}\text { Conhecer e coletar informações para o planejamento financeiro da } \\
\text { empresa. }\end{array}$ & 3,75 & 1,08 & 0,29 \\
\hline C08 & $\begin{array}{l}\text { Comparar informações financeiras da companhia (gastos em viagens } \\
\text { de 2016 versus 2015, por exemplo). }\end{array}$ & 3,97 & 0,98 & 0,25 \\
\hline C09 & Interpretar um fluxograma financeiro. & 3,76 & 1,00 & 0,27 \\
\hline C10 & Manusear calculadoras convencionais (operações simples). & 4,01 & 0,96 & 0,24 \\
\hline C11 & $\begin{array}{l}\text { Manusear calculadoras científicas (regressão logarítmica, linear, } \\
\text { exponencial, potencial). }\end{array}$ & 2,95 & 1,10 & 0,37 \\
\hline C12 & $\begin{array}{l}\text { Manusear calculadoras financeiras (juros compostos, funções } \\
\text { estatísticas, funções matemáticas). }\end{array}$ & 3,18 & 1,06 & 0,33 \\
\hline C13 & Manusear planilhas eletrônicas (Excel) para cálculos financeiros. & 4,17 & 0,88 & 0,21 \\
\hline \hline
\end{tabular}

R.G. Secr., GESEC, São Paulo, v. 9, n. 2, p 45-71, mai./ago. 2018. 


\begin{tabular}{|l|l|c|c|c|}
\hline C14 & Interpretar um cronograma financeiro. & 3,85 & 0,99 & 0,26 \\
\hline C15 & Solicitar orçamentos e cotações. & 4,38 & 0,81 & 0,18 \\
\hline C16 & $\begin{array}{l}\text { Negociar com clientes e/ou fornecedores considerando a política } \\
\text { financeira da organização. }\end{array}$ & 4,32 & 0,87 & 0,20 \\
\hline C17 & $\begin{array}{l}\text { Elaborar relatório para tomada de decisões com base nos orçamentos } \\
\text { e preços. }\end{array}$ & 4,26 & 0,83 & 0,19 \\
\hline C18 & $\begin{array}{l}\text { Utilizar aplicativos ou softwares de informática para planejamento } \\
\text { financeiro e elaboração de orçamentos. }\end{array}$ & 3,79 & 0,94 & 0,25 \\
\hline C19 & $\begin{array}{l}\text { Elaborar relatório para reembolso de despesas considerando a política } \\
\text { financeira da organização. }\end{array}$ & 4,19 & 0,89 & 0,21 \\
\hline C20 & $\begin{array}{l}\text { Utilizar aplicativos ou softwares de informática para } \\
\text { elaborar reembolsos. }\end{array}$ & 3,78 & 1,01 & 0,27 \\
\hline C21 & Identificar os principais usuários das informações contábeis. & 3,47 & 0,92 & 0,26 \\
\hline C22 & Interpretar saldo existente, saldo final e cronogramas financeiros. & 3,66 & 1,01 & 0,28 \\
\hline C23 & $\begin{array}{l}\text { Identificar as informações contidas em uma DRE (Demonstração } \\
\text { do Resultado do Exercício). }\end{array}$ & 3,44 & 1,04 & 0,30 \\
\hline C24 & Compreender o método de lançamentos contábeis da empresa. & 3,44 & 1,01 & 0,29 \\
\hline C25 & Reconhecer publicações contábeis (exemplo: Balanço Patrimonial) & 3,42 & 0,98 & 0,29 \\
\hline C26 & $\begin{array}{l}\text { Aplicar sistemas e métodos de } \\
\text { arquivos financeiros/contábeis (exemplo: Notas Fiscais). }\end{array}$ & 3,61 & 1,04 & 0,29 \\
\hline C27 & Aplicar os fundamentos e conceitos de custos. & 3,20 & 0,96 & 0,30 \\
\hline C28 & Organizar o processo de obtenção de dados referentes a custo. & 3,29 & 1,01 & 0,31 \\
\hline C29 & Elaboração de planilhas de custo utilizando Excel. & 3,79 & 1,00 & 0,26 \\
\hline C30 & Elaboração de planilhas de controle de estoque utilizando Excel. & 3,74 & 1,01 & 0,27 \\
\hline C31 & $\begin{array}{l}\text { Conhecer e coletar informações para o planejamento tributário da } \\
\text { empresa. }\end{array}$ & 3,15 & 1,13 & 0,36 \\
\hline C32 & Planejar pagamento de tributos. & 3,30 & 1,15 & 0,35 \\
\hline C33 & Organizar e arquivar documentação referente a tributos. & 3,68 & 1,16 & 0,31 \\
\hline
\end{tabular}

Fonte: Elaborado pelos autores.

Nota. Estatística descritiva das afirmações utilizadas no survey, elaborada pelo autor. As competências marcadas em cinza escuro demonstram as oito principais competências financeiras na percepção dos entrevistados, sendo consideradas, em média, muito importantes (média $\geq 4$ ). Já a competência C11, marcada em cinza claro, é a única considerada pouco importante, com média inferior a 3.

Merecem destaque as competências 15, 16, 17, 19, 13, 5, 10 e 4 (marcadas em cinza escuro) que, respectivamente, apresentam, em ordem decrescente, média maior ou igual a 4, ou seja, foram consideradas, em média, muito importantes para os respondentes. E também devese destacar a competência 11 (marcada em cinza claro), por ser o único conceito que, em média, é considerado pouco importante, com média inferior a 3. Assim, com esta pesquisa, pode-se observar que os respondentes consideram o conhecimento e aplicação de conceitos e práticas financeiras, em média, no mínimo importante para a rotina profissional, ou seja $97 \%$ das competências (32 dentre 33 possíveis) foram consideradas, em média, no mínimo importantes. 
É possível notar, ainda, mesmo antes de outros procedimentos estatísticos, que as competências consideradas mais importantes seguem uma lógica que passa pelo conhecimento dos conceitos e também da técnica, da interpretação de dados ou tarefas e, por fim, que há aplicação desses conceitos e técnicas adquiridos na formação e/ou na prática profissional.

\section{Análise fatorial exploratória}

Consiste em uma técnica que reduz o número de variáveis, para que seja mais fácil a identificação de padrões entre estas variáveis. O primeiro passo da análise fatorial é observar se os dados admitem fatoração, ou seja, avaliar o critério de Kaiser-Meyer-Olkin (KMO) e o Teste de Esfericidade de Bartlett. Deve-se lembrar que o tamanho da amostra segue Hair et al. (2005), que recomenda um $N$ de pelo menos 100 sujeitos e um número mínimo de cinco respondentes por item.

Para interpretação do KMO, índices entre 0,8 e 0,9 são considerados ótimos e excelentes, respectivamente. Assim, os dados estão aptos a serem fatorados, apresentando como resultado 0,938. Já no Teste de Esfericidade de Bartlett é indicado que o nível de significância tenha níveis de $\mathrm{p}<0,05$, o que, mais uma vez, comprova que os dados são fatoráveis com o resultado de 0,00. Em geral, esses dois testes tendem a ser uniformes, ou seja, ou aprovam ou rejeitam os dados analisados (Damásio, 2012; Hair et al. 2005).

Foi usado o método de máxima verossimilhança para extração dos dados. Para rotação dos fatores, o método de rotação oblíqua oblimin direto, porque esse tipo de rotação tem como premissa que os itens sejam correlacionados entre si. Nesse modelo, utilizando-se o software SPSS, sem limitação dos fatores, foi sugerido pelo programa o uso de cinco fatores. Porém, após analisar a variância total explicada e o gráfico de escarpa (eigenvalues maiores que 1), optou-se por usar apenas três fatores, já que os outros dois apresentavam eigenvalues muito próximos a 1 (Damásio, 2012; Hair et al., 2005).

Apesar da literatura indicar o uso de itens com comunalidades $>0,5$, notou-se que os itens com comunalidades entre 0,5 e 0,6 apresentavam cargas fatoriais em mais de um fator. $\mathrm{Na}$ busca de fatores fortemente explicados, com carga fatorial $>0,600$, foram retirados os itens que apresentavam comunalidades inferior a 0,60 (totalizando 19 itens excluídos). Assim, no novo modelo, foram utilizados apenas 14 itens e três fatores, conforme Tabela 2. O uso de cinco fatores com todos os itens explicava, de maneira acumulada, $62,7 \%$ da amostra, enquanto o uso 
de três fatores (com 14 itens) explica 70\%. Os dados continuaram apresentando bons índices para fatoração: KMO de 0,890 e Teste de Esfericidade de Bartlett de 0,00 (Damásio, 2012).

Para avaliar a confiabilidade da estrutura fatorial, foi calculado o Alfa de Cronbach (índice de consistência interna), esperando-se que o resultado fosse $>0,70$, que é um índice aceitável. A estrutura analisada apresenta como resultado 0,915 e os itens, individualmente, resultados entre 0,905 e 0,914, considerados excelentes em uma fatoração (Damásio, 2012).

Assim, chegou-se a uma proposta de Escala de Competências Financeiras para Profissionais de Secretariado. Ela é composta por 14 itens e três fatores que foram denominados como: Conceito, Interpretação de Informações e Aplicação, seguindo o grupo de competências contidos em cada fator. Vale ressaltar que seis das oito competências consideradas muito importantes pelos entrevistados fazem parte dessa escala e foram marcadas de cinza escuro.

Tabela 2 - Escala de Competências Financeiras para Profissionais de Secretariado.

\begin{tabular}{|l|c|c|c|}
\hline \multicolumn{1}{|c|}{ Afirmações } & \multicolumn{2}{c|}{ Fatores } \\
\cline { 2 - 4 } & $\begin{array}{c}\text { F1 } \\
\text { Conceitos }\end{array}$ & $\begin{array}{c}\text { Interpretação } \\
\text { Informações }\end{array}$ & $\begin{array}{c}\text { F3 } \\
\text { Aplicação }\end{array}$ \\
\hline $\begin{array}{l}\text { Conhecer e coletar informações para o planejamento tributário da } \\
\text { empresa. }\end{array}$ & 0.904 & & \\
\hline Reconhecer publicações contábeis (exemplo: Balanço Patrimonial). & 0.805 & & \\
\hline Planejar pagamento de tributos. & 0.797 & & \\
\hline $\begin{array}{l}\text { Identificar as informações contidas em uma DRE (Demonstração } \\
\text { do Resultado do Exercício). }\end{array}$ & 0.784 & & \\
\hline Organizar o processo de obtenção de dados referentes a custo. & 0.783 & & \\
\hline Compreender o método de lançamentos contábeis da empresa. & 0.783 & & \\
\hline Aplicar os fundamentos e conceitos de custos. & 0.760 & & 0.701 \\
\hline Interpretar informações que contenham descontos. & & -0.927 & \\
\hline Interpretar informações que contenham juros e/ou acréscimos. & & -0.858 & \\
\hline Interpretar informações que contenham porcentagens. & & -0.824 & 0.787 \\
\hline $\begin{array}{l}\text { Negociar com clientes e/ou fornecedores considerando a política } \\
\text { financeira da organização. }\end{array}$ & & & 0.946 \\
\hline Solicitar orçamentos e cotações. & & & \\
\hline $\begin{array}{l}\text { Elaborar relatório para tomada de decisões com base nos } \\
\text { orçamentos e preços. }\end{array}$ & & & \\
\hline $\begin{array}{l}\text { Elaborar relatório para reembolso de despesas considerando a } \\
\text { política financeira da organização. }\end{array}$ & & & \\
\hline
\end{tabular}

Fonte: Elaborado pelos autores

Nota. Escala de competências financeiras para o profissional de secretariado, produzida pelo autor no software SPSS, por meio de análise fatorial exploratória, usando os dados coletados na survey.

Após a análise fatorial exploratória e criação da escala através de fatores comuns presentes no questionário aplicado, foi possível mensurar as competências financeiras do R.G. Secr., GESEC, São Paulo, v. 9, n. 2, p 45-71, mai./ago. 2018. 
profissional de secretariado, por meio do modelo apresentado, uma vez que o instrumento trata do embasamento teórico e confirmação estatística de todas as fases, através da análise fatorial exploratória.

Contudo, é importante estabelecer uma conexão entre a análise estatística e a realidade profissional dos entrevistados. Assim, analisando a Figura 1, pode-se entender como a escala aqui proposta interage na rotina dos profissionais. A partir da formação, obtêm-se os conceitos financeiros necessários para interpretar informações oriundas, na maior parte do tempo, de dados vindos do mercado. Interpretando-se com os conceitos adquiridos, é possível gerar um novo conhecimento e, com isso, aplicar tal resultado em sua realidade profissional, sempre levando em consideração o contexto corporativo do profissional.

Figura 1 - Processo de interação entre os fatores resultantes da análise fatorial exploratória e a rotina do profissional de secretariado.

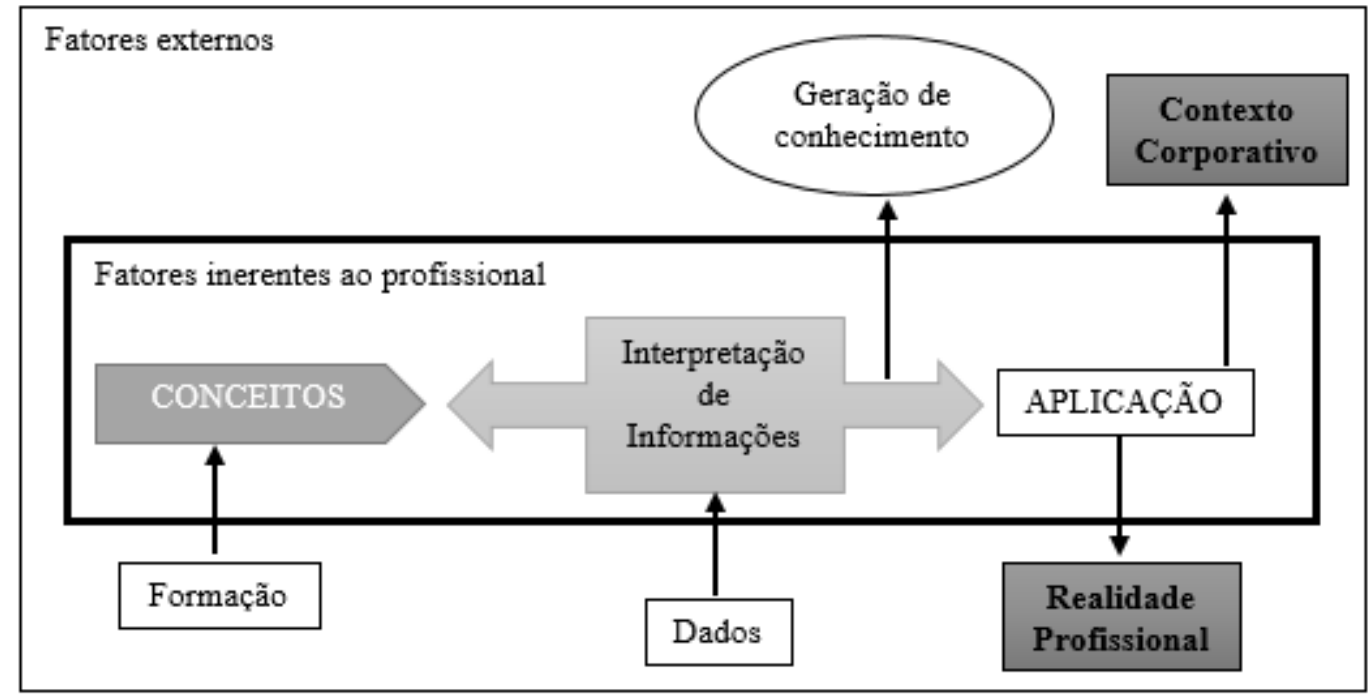

Fonte: Elaborado pelos autores

Em complemento à análise fatorial, foram realizadas regressões lineares múltiplas, no software SPSS, entre os 33 itens do questionário que abordam as competências financeiras e também os três fatores resultantes da análise fatorial (variáveis dependentes) e os dados dos respondentes (variáveis independentes), ou seja, a parte demográfica. Tal procedimento visou encontrar relações estatisticamente significantes entre os respondentes e as respostas coletadas em todos os itens. Os principais resultados são apresentados na Tabela 3. As regressões seguiram o padrão: análise de correlações, $\mathrm{R}$ quadrado e $\mathrm{R}$ quadrado ajustado, teste Anova respeitando a significância de 0,005 e análise dos coeficientes (Wooldridge, 2014). 
A partir da significância estatística e dos coeficientes é possível interpretar a relação entre as variáveis. Optou-se por não usar equações matemáticas, na tentativa de aproximar as interpretações estatísticas à realidade dos profissionais. Importante salientar que não há, na produção científica da área secretarial, teoria que embase as interpretações.

Registre-se que faixa etária apresenta relação positiva com a interpretação de indicadores financeiros e também com a identificação de informações contidas em uma DRE, ou seja, quanto maior a faixa etária e possivelmente maior senioridade (experiência profissional), há uma percepção de que essas competências são mais importantes na atividade do profissional de secretariado. 


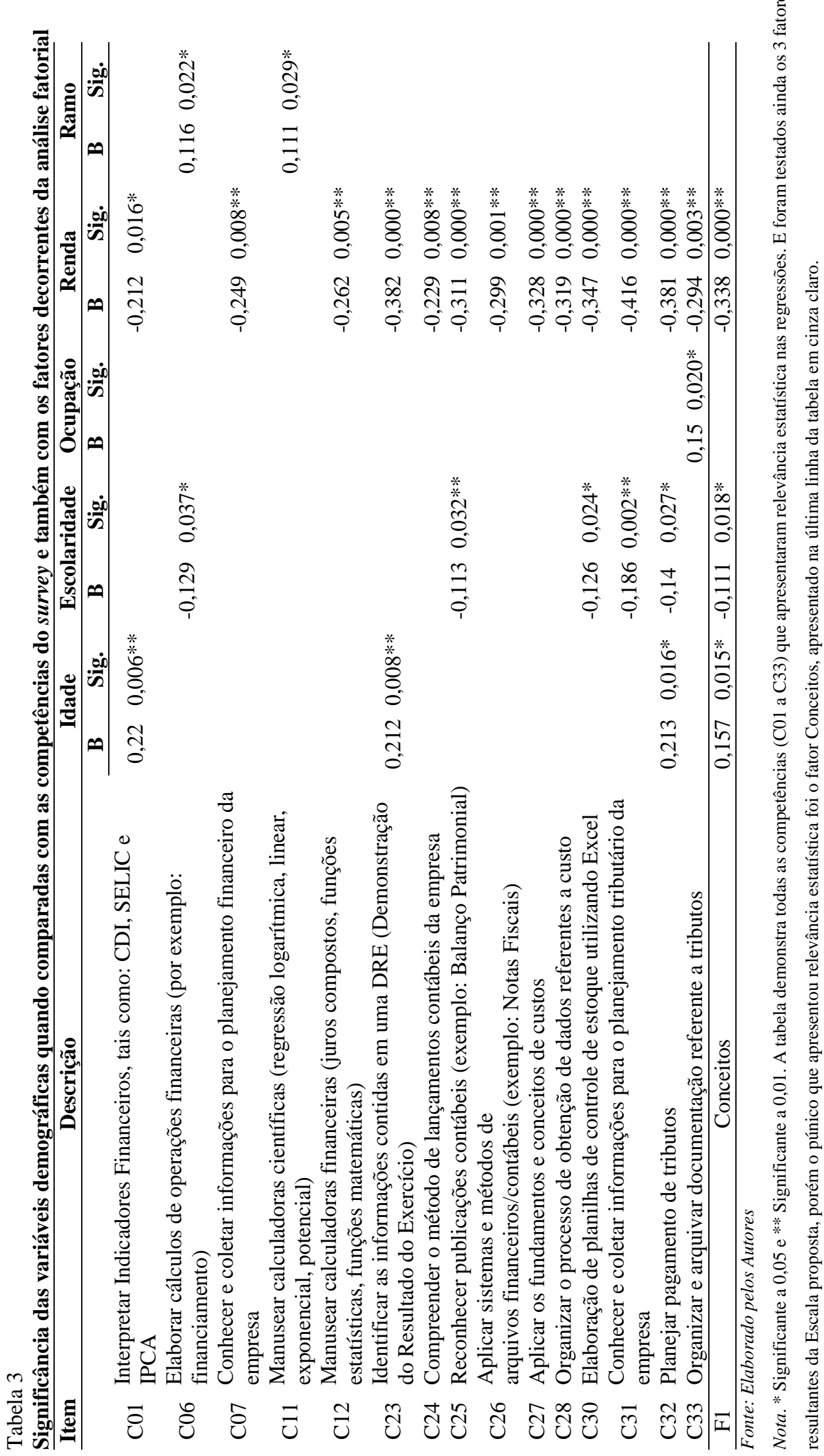


Escolaridade apresenta relação negativa com a elaboração de cálculos de operações financeiras, reconhecimento de publicações contábeis, elaboração de planilhas de controle de estoque utilizando Excel, conhecimento e coleta de informações para o planejamento tributário da empresa e planejamento de pagamento de tributos, o que demonstra que profissionais com menos escolaridade têm a percepção de que tais competências são mais importantes. Tal análise permite inferir que pessoas com um menor grau de escolaridade exercem uma gama maior de tarefas operacionais.

Renda Bruta apresenta uma relação interessante com as competências analisadas, levando em consideração a carreira do profissional de secretariado. Por apresentar relação negativa com 13 competências (C01, C07, C12, C23, C24, C25, C26, C27, C28, C30, C31, C32 e C33), a interpretação é a de que quanto maior a percepção de importância de tais competências, menor é a renda bruta individual. Assim, é possível concluir que quanto mais alto o cargo e, consequentemente, a renda bruta individual, menor é a percepção de que essas competências são importantes em sua rotina. Possivelmente, os profissionais que atendem altos executivos concentram-se mais nas demandas do executivo do que propriamente na rotina operacional da empresa.

"Ramo da Empresa" apresenta uma relação positiva com as competências "elaborar cálculos de operações financeiras" (por exemplo: financiamento) e "manusear calculadoras científicas" (regressão logarítmica, linear, exponencial, potencial). Dessa forma, os profissionais que trabalham em empresas financeiras têm uma percepção de que essas duas competências são mais importantes para sua rotina.

Por fim, apenas o fator "Conceitos (F1)" apresenta relação estatística significativa com as competências, sendo: a) idade, em que a relação é positiva e a interpretação é a de que quanto maior a faixa de idade, maior a percepção de importância dos conceitos financeiros; b) escolaridade, que apresenta relação negativa, demonstrando que quanto maior a escolaridade, menor a percepção de importância dos conceitos; e c) renda, que vai ao encontro da análise já realizada, apresentando relação negativa, o que permite interpretar que quanto maior a renda bruta individual, menor a percepção de importância dada aos conceitos financeiros aqui investigados. 


\section{Considerações Finais}

O principal objetivo deste estudo foi contribuir para a percepção da importância das competências financeiras para profissionais de secretariado. Considera-se que esse objetivo foi alcançado, uma vez que, na pesquisa, foram identificadas oito competências percebidas como muito importantes para a rotina do profissional. Também foi possível alcançar os objetivos específicos, propondo-se uma escala de competências financeiras, que leva em consideração três fatores: conceitos, interpretação de dados e aplicação desses dados. Além disso, foi possível perceber os efeitos que variáveis como: idade, escolaridade, ocupação, renda e ramo de atuação da empresa têm sobre as respostas, influenciando-as e apresentando relevância estatística.

Nesse sentido, ainda foi possível responder às perguntas que nortearam o artigo: a) podendo-se chegar à conclusão de que, em média, os participantes da pesquisa percebem as competências financeiras como importantes para sua rotina profissional; e b) que existem oito competências percebidas como mais pertinentes e uma competência percebida como menos pertinente a esse profissional.

Este estudo traz também uma contribuição teórica, ou seja, mapeou as principais competências financeiras exigidas pelas empresas, na percepção dos profissionais de secretariado. E ainda apresenta contribuições práticas: a) facilitando a identificação das principais competências financeiras dos profissionais de secretariado, por meio da pesquisa aplicada e análise dos dados coletados; b) criando uma ferramenta para a área de recursos humanos e contratantes em geral, na identificação das principais competências financeiras desse profissional, por meio da Escala de Competências Financeiras do Profissional de Secretariado; e, por fim, c) auxiliando as instituições de ensino que oferecem os cursos de secretariado a analisar se as disciplinas que envolvem finanças estão baseadas, de alguma forma, nas dimensões propostas pela escala: conceito, interpretação de informações e aplicação. Além de também demonstrar os principais conceitos e uso de tais competências exigidas pelo mercado de trabalho na percepção desses profissionais.

O trabalho possibilita ainda uma reflexão sobre os cursos de secretariado e o ensino de disciplinas, tais como: matemática financeira, contabilidade e economia, que geralmente têm um viés mais teórico dentro do curso. $\mathrm{O}$ que de certa forma vai de encontro à pesquisa que mostrou que o profissional de secretariado tem uso prático de tais competências e habilidades. Desta forma é interessante que os cursos trabalhem mais a prática, com exercícios e estudos de caso próximos a realidade, estimulando assim o entendimento dos conceitos e sua aplicação. 
O estudo apresenta limitações de teoria, método e amostra: a) o número reduzido de trabalhos que abordam o tema finanças e secretariado e, consequentemente, a falta de publicações com a mesma temática, que utilizem análises estatísticas; b) a amostra não permite que os resultados sejam generalizados para todos os profissionais da área; e, por fim, c) é importante ressaltar que a Escala de Competências para Profissionais de Secretariado foi validada apenas estatisticamente, assim sugere-se a aplicação do instrumento junto aos profissionais da área e posterior revalidação da mesma.

Ainda nesse contexto, tais limitações abrem possibilidades de novos estudos, já que a identificação das principais competências financeiras significa um importante avanço para a área secretarial, que não contava com nenhum estudo nessa linha, potencializando um novo e vasto campo de pesquisa. E, também, com a proposição de uma escala, permite-se que os próximos estudos possam explorar, por exemplo, se essas realmente são as competências essenciais na visão dos executivos ou, ainda, se os resultados aqui apresentados seriam os mesmos, caso aplicado o questionário em cidades, instituições e modalidades de cursos diferentes.

\section{Referências}

Almeida, R. (2010). Os territórios de uma profissão: Secretariado Executivo. Revista Eletrônica Gestão e Serviços, 1(1), 26-36.

Barros, C. D. M. P.; Silva, J. S.; Lima, G. A.; \& Brito, D. G. S. (2013). As competências gerenciais desenvolvidas pelos secretários executivos. Revista de Gestão $e$ Secretariado, 4(2), 25-47.

Bilert, V. S. \& Biscoli, F. V. (2012). Perfil dos discentes (ingressantes e concluintes) de Secretariado Executivo: Um estudo comparativo nas instituições de ensino superior (IES) públicas. Revista de Gestão e Secretariado, 2(2), 33-57.

Bonzanini, S. H. S. (2011). O profissional de secretariado executivo nas relações internacionais. Revista de Gestão e Secretariado, 1(2), 142-161.

Boyatzis, R. E. (2008). Competencies in the 21st century. Journal of Management Development, 27(1), 5-12. 
Campos, H., Jr.; Barbero, E. R.; \& Lourenço, C. E. (2015, novembro). Validação nomológica de escala multidimensional para maturidade da indústria: Evidências empíricas no Brasil. Anais dos Seminários em Administração, São Paulo, SP, Brasil, 18. Recuperado de http://sistema.semead.com.br/18semead/resultado/trabalhosPDF/729.pdf

Cardoso, R. L.; Riccio, E. L.; \& Albuquerque, L. G. (2009). Competências do contador: Um estudo sobre a existência de uma estrutura de interdependência. Revista de Administração - RAUSP, 44(4), 365-379.

Centro Estadual de Educação Tecnológica Paula Souza (2011). Plano de curso para a habilitação profissional de técnico em secretariado. Recuperado de http://www.etelg.com.br/paginaete/cursos/planos/planocurso/pc_secretariado.pdf.

Cielo, I. D. \& Cielo, L. C. (2007). A importância dos conhecimentos em gestão financeira para os profissionais de secretariado executivo. Revista Expectativa, 5(5), 147-155.

Cielo, I. D.; Schmidt, C. M.; \& Wenningkamp, K. R. (2014). Secretariado executivo no Brasil: Quo Vadis? Revista de Gestão e Secretariado, 5(3), 49-70.

Classificação Brasileira de Ocupações - CBO, aprovada pela Portaria Ministerial 397, de 9 de outubro de 2002. Recuperado de http://www.mtecbo.gov.br/

Cooper, D. R. \& Schindler, P. S. (2016). Métodos de pesquisa em administração. Porto Alegre: McGraw Hill Brasil.

Costa, L. V. (2013). Construção e validação de uma escala de percepção de sucesso na carreira. Revista de Carreiras e Pessoas (ReCaPe), 3(1), 2-19.

Damásio, B. F. (2012). Uso da análise fatorial exploratória em psicologia. Avaliação Psicológica, 11(2), 213-228.

Dodman, M. (2016). Knowledge and competence. Key concepts in an educational paradigm for a sustainable society. Visions for Sustainability, 5, 15-27.

Dutra, J. S.; Hipólito, J. A. M.; \& Silva, C. M. (2000). Gestão de pessoas por competências: O caso de uma empresa do setor de telecomunicações. Revista de Administração Contemporânea, 4(1), 161-176.

R.G. Secr., GESEC, São Paulo, v. 9, n. 2, p 45-71, mai./ago. 2018. 
Euflausino, E. \& Silva, J. O. (2015). A imagem do profissional de Secretariado Executivo em anúncios publicitários. Revista Unifamma, 14(2), 1-18. Recuperado de http://revista.famma.br/unifamma/index.php/RevUNIFAMMA/article/view/176/110.

Faria, D. S.; Baêta, O. V.; \& Faria, D. A. (2015). Secretariado Executivo: Análise bibliográfica do perfil requerido pelo mercado de trabalho. Revista de Ciências Jurídicas $e$ Empresariais, 13(2), 117-122.

Fernandes, B. H. R.; Fleury, M. T. L.; \& Mills, J. (2006). Construindo o diálogo entre competência, recursos e desempenho organizacional. RAE-Revista de Administração de Empresas, 46(4), 48-65.

Ferraz, A. P. C. M. \& Belhot, R. V. (2010). Taxonomia de Bloom: Revisão teórica e apresentação das adequações do instrumento para definição de objetivos instrucionais. Gestão \& Produção, 17(2), 421-431

Fleury, M. T. L. \& Fleury, A. (2001). Construindo o conceito de competência. Revista de Administração Contemporânea, 5(spe), 183-196.

Fleury, M. T. L. \& Fleury, A. C. C. (2004). Alinhando estratégia e competências. Revista de Administração de Empresas, 44(1), 44-57.

Fontanella, R. (2012). Os tipos comportamentais dos executivos e a postura do profissional de secretariado. Revista de Gestão e Secretariado, 2(2), 79-104.

Gretha-Taylor, H. (2008). Identifying collaborative competencies. Review of Public Personnel Administration, 28(2), 103-119.

Hair, J. F., Jr.; Anderson, R. E.; Tatham, R. L., \& Black, W. C. (2005). Análise multivariada de dados. Porto Alegre: Bookman.

Laffin, M. (2015). Graduação em Ciências Contábeis: a ênfase nas competências: contribuições ao debate. Arquivos analíticos de políticas educativas, 23(78), 1-30. Recuperado de http://cm.redalyc.org/articulo.oa?id=275041389048. 
Leal, F. G. \& Dalmau, M. B. L. (2014). Análise das competências secretariais requeridas pela Universidade Federal de Santa Catarina em comparação ao perfil profissiográfico do secretário executivo. Revista de Gestão e Secretariado, 5(3), 143-174.

Leal, F. G.; \& Fiates, G. G. S. (2013). Competências dos secretários-executivos de uma Universidade Pública Federal: Uma Análise a partir da perspectiva dos gestores. Revista de Gestão e Secretariado, 4(3), 30-57.

Leal, F. G. \& Moraes, M. C. B. (2017). Perspectivas de atuação do Secretário Executivo na gestão da internacionalização da educação superior. Revista de Gestão e Secretariado, 8(1), 138-167.

Lei $n^{\circ} 7.377$, de 30 de setembro de 1985. Dispõe sobre o exercício da profissão de Secretário e dá outras providências. Recuperado de http://www.planalto.gov.br/ccivil_03/leis/L7377.htm.

Lei $n .^{\circ} 9.261$, de 10 de janeiro de 1996. Altera a redação dos incisos I e II do art. $2^{\circ}$, o caput do art. $3^{\circ}$, o inciso VI do art. $4^{\circ}$ e o parágrafo único do art. $6^{\circ}$ da Lei $\mathrm{n}^{\circ} 7.377$, de 30 de setembro de 1985. Recuperado de http://www.planalto.gov.br/ccivil_03/leis/L9261.htm.

Mascarenhas, M. H. S.; Sepulveda, F. A. M.; \& D’Assumpção, E. S. (2011). Sistema de gestão integrado: A atuação do secretário executivo. Revista de Gestão e Secretariado, 2(1), 177 192.

McClelland, D. C. (1973). Testing for competence rather than for "intelligence". American Psychologist, 28(1), 1-14.

Morais, P. A. P.; Melo, T. A. \& Bianco, M. F. (2015). Noções/significado (s) de competência (s): Uma revisão teórica. Revista Cesumar Ciências Humanas e Sociais Aplicadas, 20(2) 487-504.

Moreira, K. D.; Rodrigues, L. M. A.; Vale, J. C. F.; \& Rosa, M. H. (2016). As competências contemporâneas do secretário executivo e a relação com as competências do Middle Manager. Revista de Gestão e Secretariado, 7(1), 45-66.

Moreira, K. D.; Santos, A. K.; \& Moretto Neto, L.; (2015). Profissional de secretariado empreendedor: Um agente de mudança. Revista de Gestão e Secretariado, 6(1), 168-186. 
Moura, M. D. C. S.; \& Sobral, M. F. F. (2014). Gestão por competências com uso da metodologia multicritério na avaliação de profissionais de apoio administrativo de um Call Center. Revista de Gestão e Secretariado, 5(3), 1-27.

Pereira, K. A. \& Silva, M. R. (2014). A atuação do secretário executivo no terceiro setor na cidade de Aracaju. Revista de Gestão e Secretariado, 5(1), 104-130.

Resolução $n^{o}$ 3, de 23 de junho de 2005. Institui as Diretrizes Curriculares Nacionais para o curso de graduação em Secretariado Executivo e dá outras providências. Recuperado de http://portal.mec.gov.br/cne/arquivos/pdf/rces003_05.pdf.

Rodrigues, L. M. A. \& Lavarda, R. A. B. (2016, Junho). Secretarial assistant professional: The role as information manager in the strategy formation process. International Conference on Information Systems and Technology Management. São Paulo, SP, Brasil, 13. Recuperado de http://www.contecsi.fea.usp.br/envio/index.php/contecsi/13CONTECSI/ paper/view/4216/2696.

Rodrigues, A. A.; Rosa, J. S.; Ferko, G. P. S.; \& Melo, M. M. B. (2017). Empregabilidade profissional: O secretariado executivo em foco na Amazônia Setentrional. Revista de Gestão e Secretariado, 7(3), 66-95.

Sabino, R. F. \& Andrade, J. A. F., Jr. (2011). Secretariado: Formação e mercado no estado de Sergipe. Revista de Gestão e Secretariado, 2(1), 6-31.

Santos, A. P. (2014). Conhecimentos, habilidades e atitudes: O conceito de competências no trabalho e seu uso no setor público. Revista do Serviço Público, 62(4), 369-386.

Santos, P. M. D. (2011). Secretariado: Um fator de competitividade organizacional. Recuperado de http://repositorio.ipv.pt/bitstream/10400.19/984/1/ SECRETARIADO_COMPETITIVIDADE_PAULA\%20SANTOS.pdf

Schmitz, C. J.; Battisti, P. S. S.; \& Santos, S. R. F. (2015). Uma análise da consultoria secretarial como novo nicho de mercado e como disciplina nos cursos de Secretariado Executivo. Revista de Gestão e Secretariado, 6(2), 19-43. 
Silva, J. S.; Barros, C. D. M. P.; \& Nascimento, A. S. S. (2016). Cenário da produção bibliográfica nacional em secretariado nos anos de 2004 a 2013. Revista Capital CientíficoEletrônica, 14(2), 60-75.

Siqueira, M. M. M. (2009). Medidas do comportamento organizacional: Ferramentas de diagnóstico e de gestão. Porto Alegre: Artmed Editora.

Spencer, L. M. \& Spencer, S. M. (1993). Competence at work: Models for superior performance. New York: John Wiley\& Sons.

Todorov, M. D. C. A.; Kniess, C. T.; \& Chaves, M. S. (2013). As competências do profissional de secretariado na implantação de projetos sustentáveis. Revista de Gestão $e$ Secretariado, 4(3), 189-209.

Todorov, M. D. C. A.; Martins, C. B.; Genghini, L. A.; Martins, S. B.; \& Kniess, C. T. (2016). Executive secretariat: Profession trends in a world increasingly dynamic. International Journal of Professional Business Review, 1(1), 15-29.

Wooldridge, J. (2014). Introdução à econometria: Uma abordagem moderna. São Paulo: Cengage Learning. 